
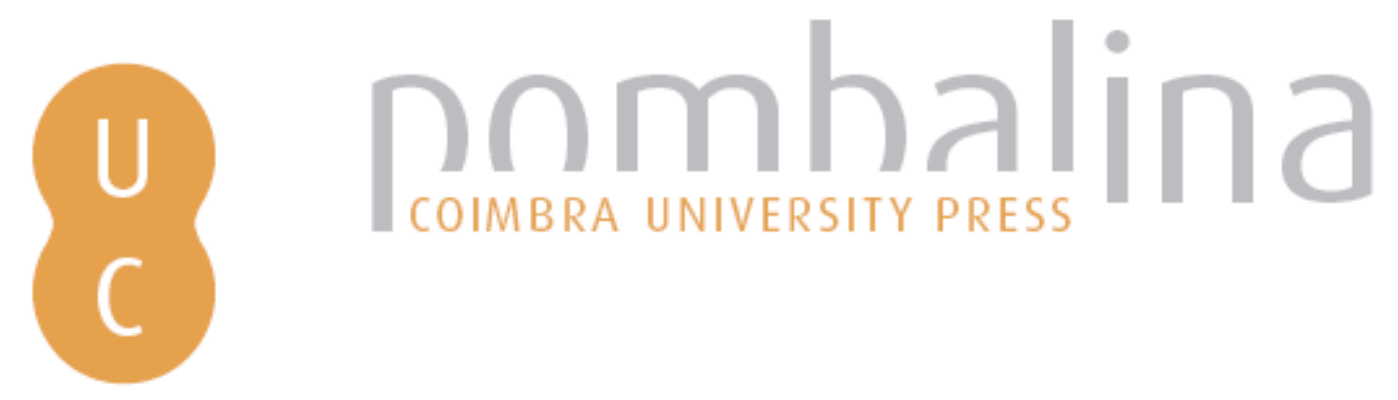

\title{
Searching for a reliable remote sensing method to detect burned area scars for the Andean Cusco region in Southern Peru
}

Autor(es): $\quad$ Planas, E.; Guix, A.; Pastor, E.; Oliveras, I.

Publicado por: Imprensa da Universidade de Coimbra

URL

persistente: URI:http://hdl.handle.net/10316.2/34270

DOI: $\quad$ DOI:http://dx.doi.org/10.14195/978-989-26-0884-6_101

Accessed : $\quad$ 26-Apr-2023 07:13:14

A navegação consulta e descarregamento dos títulos inseridos nas Bibliotecas Digitais UC Digitalis, UC Pombalina e UC Impactum, pressupõem a aceitação plena e sem reservas dos Termos e Condições de Uso destas Bibliotecas Digitais, disponíveis em https://digitalis.uc.pt/pt-pt/termos.

Conforme exposto nos referidos Termos e Condições de Uso, o descarregamento de títulos de acesso restrito requer uma licença válida de autorização devendo o utilizador aceder ao(s) documento(s) a partir de um endereço de IP da instituição detentora da supramencionada licença.

Ao utilizador é apenas permitido o descarregamento para uso pessoal, pelo que o emprego do(s) título(s) descarregado(s) para outro fim, designadamente comercial, carece de autorização do respetivo autor ou editor da obra.

Na medida em que todas as obras da UC Digitalis se encontram protegidas pelo Código do Direito de Autor e Direitos Conexos e demais legislação aplicável, toda a cópia, parcial ou total, deste documento, nos casos em que é legalmente admitida, deverá conter ou fazer-se acompanhar por este aviso.

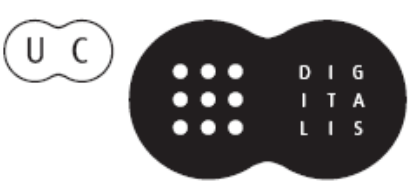




\section{ADVANCES IN}

Forest Fire

\section{RESEARCH}

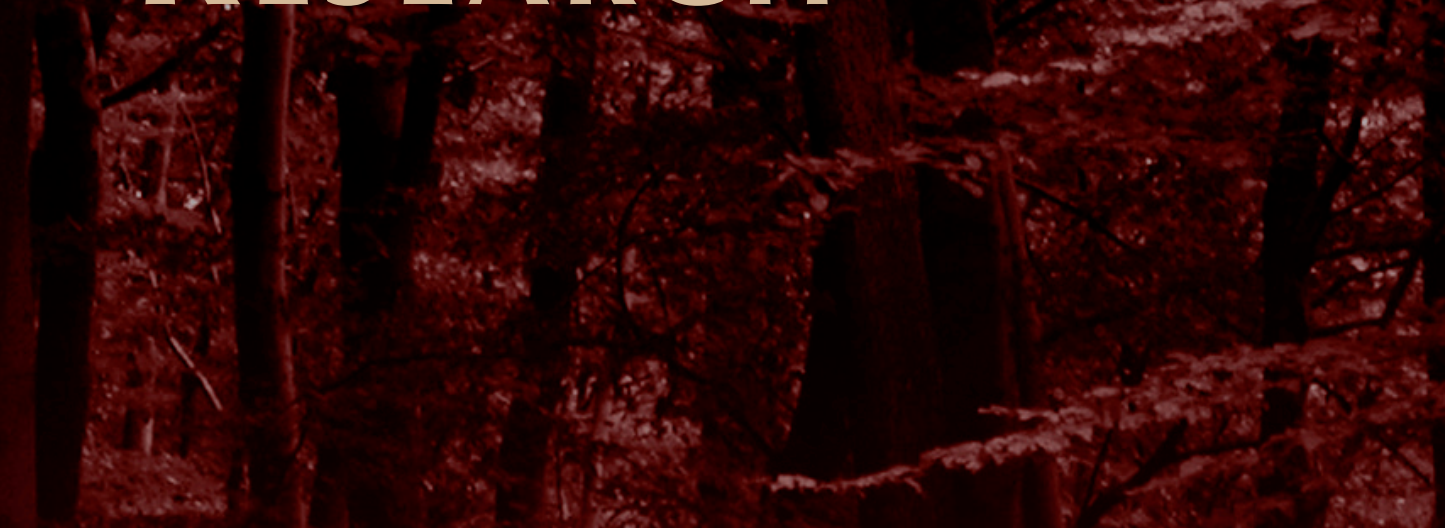

\section{DOMINGOS XAVIER VIEGAS}

\section{EDITOR}




\title{
Searching for a reliable remote sensing method to detect burned area scars for the Andean Cusco region in Southern Peru
}

\author{
E. Planas ${ }^{\mathrm{a}}$, A. Guix ${ }^{\mathrm{a}}$, E. Pastor ${ }^{\mathrm{a}}$, I. Oliveras $^{\mathrm{b}, \mathrm{c}}$ \\ ${ }^{a}$ Department of Chemical Engineering, Centre for Technological Risk Studies, Universitat \\ Politècnica de Catalunya-BarcelonaTech, Diagonal 647, E-08028 Barcelona, Catalonia, Spain. \\ eulalia.planas@upc.edu, alan.guix@upc.edu, elsa.pastor@upc.edu \\ ${ }^{b}$ Environmental Change Institute, School of Geography and the Environment, University of Oxford, \\ South Parks Road OX13QY Oxford, UK. imma.oliveras@ouce.ox.ac.uk \\ ${ }^{c}$ Nature Conservation and Plant Ecology Group, Wageningen University, Building 100, \\ Droevendaalsesteg 3', 6708PB Wageningen, Netherlands.
}

\begin{abstract}
According to the literature, MODIS burned area product MCD45 has been shown to have low reliability in the tropical Andes, with omission errors around 50\%. Instead, Landsat images can provide good results but current processing methodologies are very time consuming. This study presents a new method for the tropical Andes, based on spectral unmixing applied to MODIS and Lansat images, with the aim of improving the methods currently available to estimate burned area in the region. Results show that the technique is not appropriate for MODIS images, which have not enough spatial resolution distinguishing between burned and unburned pixels. However, spectral unmixing applied to Landsat images lead to results with only $20 \%$ of omission errors and $9 \%$ of commission errors.
\end{abstract}

Keywords: tropical mountain cloud forest, linear unmixing, Peruvian Andes, MODIS, Landsat TM5

\section{Introduction}

The Andes are one of the most biologically rich regions on the planet, where the occurrence of fires is believed to be increasing. In the Andean region of Cusco there are, on the one hand, high mountain pastures where the use of fire by local communities for agriculture and livestock as well as for cultural and religious practices is common (Sarmiento \& Frolich, 2002). On the other hand, there are the tropical mountain cloud forests, ecosystems of high ecological value but extremely sensitive to fire which, due to climate change, are being increasingly affected by fires (Cochrane, 2003). However, the fire regime and the emissions associated with the combustion of biomass in the region are still relatively poorly understood, mainly due to the lack of systematic national fire monitoring policies but also due to the characteristics of the region with very remote areas of difficult access. Remote sensing can therefore become a very effective tool for the estimation of burned areas in these regions.

There are numerous studies in the literature on the detection of burned area scars from satellite images, but there are really very few studies focused on the Tropical Andean region (Bradley \& Millington, 2006; Oliveras, Anderson, \& Malhi, 2014; Román-Cuesta et al., 2014). Moreover, all of these few studies also agree that the majority of remote sensing products currently used have a high degree of underestimation in the detection of the number and area of fires in this region. Several reasons can be argued to explain this underestimation (Bradley \& Millington, 2006), mainly: spatial resolution of imagery, topographic effects causing shadows on the image, climatic seasonality which affects fuel moisture contents and cloud cover, local fire characteristics (most fires in the tropical Andes are small and of short duration) and the spatial and temporal scales of human activity in managing the grasslands. Oliveras et al. (Oliveras et al., 2014) observed a remarkable underestimation of fire ignitions and burned area from MODIS fire products. Particularly, their data suggested that the MODIS burned area product (MCD45) failed to detect not only small burn scars but also large burn scars, probably due to the limitation of this global algorithm to overcome issues of cloud frequency and shadows caused by

Advances in Forest Fire Research - Page 928 
the complex topography of this region. These authors have therefore suggested that a calibration would be needed for the Tropical Andes in order to improve the performance of these products. The use of higher resolution images such as the ones provided by the Landsat thematic mapper could also be a solution, but current processing methodologies are very time consuming, of difficult validation and limited by the temporal resolution of the Landsat imagery.

The basic unit of a satellite image is the pixel that varies in size depending on the image's resolution. Regardless its resolution, a pixel is not usually homogeneous, because the signal measured by the sensor is always a mixture of the electromagnetic radiation of different constituents that are in pixels. Recognizing that pixels are combinations of different components has introduced the need to decompose quantitatively these mixtures. The basic premise of the mixture modelling techniques is that in an image most of the area is dominated by a small number of different materials that have relatively constant spectral properties. These materials (eg water, soil, metal, vegetation, etc.) are called endmembers and the fractions appearing in a mixed pixel are called abundances. The endmembers are elements considered spectrally pure. The spectral decomposition or spectral unmixing is thus the procedure by which the measured spectrum of a mixed pixel is decomposed into the endmembers and their corresponding abundances. During the last decades, several methods have been proposed to solve the mixture problem (Atkinson \& Tatnall, 1997; Brown, Gunn, \& Lewis, 1999; Carpenter, Gopal, Macomber, Martens, \& Woodcock, 1999; Guilfoyle, Althouse, Chang, \& Member, 2001; Nascimento \& Dias, 2005; Wang, 1990). Among all methods, the most widely used is the spectral mixture analysis (Adams, Smith, \& Johnson, 1986; Keshava \& Mustard, 2002) using linear models (LMM) and non linear models (NLMM). The question of whether linear or nonlinear processes dominate spectral signatures is still an unsolved problem (Somers, Asner, Tits, \& Coppin, 2011). The linear approach has proven to be a useful technique for the interpretation of remote sensing data variability and a powerful mean of converting spectral information on products which may be related to the abundance of natural materials on the surface (Keshava \& Mustard, 2002). Nevertheless, it does not include the possible interactions between the endmembers present in a pixel, which may lead to results with absolute errors of up to $30 \%$. The NLMM, although it considers the possible interactions between endmembers and thus reduces the error, has a much higher computational cost (Adams \& Gillespie, 2006). For this reason, the use of LMM is much more extensive in the literature.

The key to achieve good results in spectral mixture analysis is an accurate selection of type and umber of endmembers (Elmore, Mustard, Manning, \& Lobell, 2000; Tompkins, Mustard, \& Forsyth, 1997). The most common way achieving this is the use of iterative testing with different combinations and sets of endmembers (Franke, Roberts, Halligan, \& Menz, 2009; Somers et al., 2010). Once the endmembers have been determined and the number of spectral bands available is known, if a LMM is used, an overdetermined system of linear equations have to be solved in order to obtain, for each pixel, the respective abundances of the endmembers. The solving method used must ensure the minimum error of the solution. Generally, the selection of this method is arbitrary, for example (Ball, Kari, \& Younan, 2004) use the singular value decomposition, (Adams et al., 1995) use the Gramm-Schmidt orthogonalization, (Chen, Jia, Yang, \& Matsushita, 2009; Du, 2004) use quadratic programming, (Settle, 2006) uses maximum similarity and (Anderson et al., 2005; Barducci \& Mecocci, 2005) use the least squares regression analysis.

This study aims to develop a systematic and reliable methodology for obtaining accurate data on burned area scars for the Tropical andes, by using unmixing modelling on remote sensing images from different satellites (MODIS and Landsat).Following the work performed by Anderson et al. (Anderson et al., 2005), we used three types of endmembers (soil, vegetation and water), performing a specific study to characterize them (Somers et al., 2011) for the study area. 


\section{Study area}

The study area, of about 2.8 million hectares, is located on the eastern slope of the southeastern Peruvian Andes, at altitudes over 2000 meters above sea level (see the red line in Figure 1), and is characterized by very steep gradients both longitudinally and latitudinally. The coordinates used to delimitate the study area were: $-12^{\circ} \mathrm{S},-14^{\circ} \mathrm{S},-69.5^{\circ} \mathrm{W},-73.2^{\circ} \mathrm{W}$

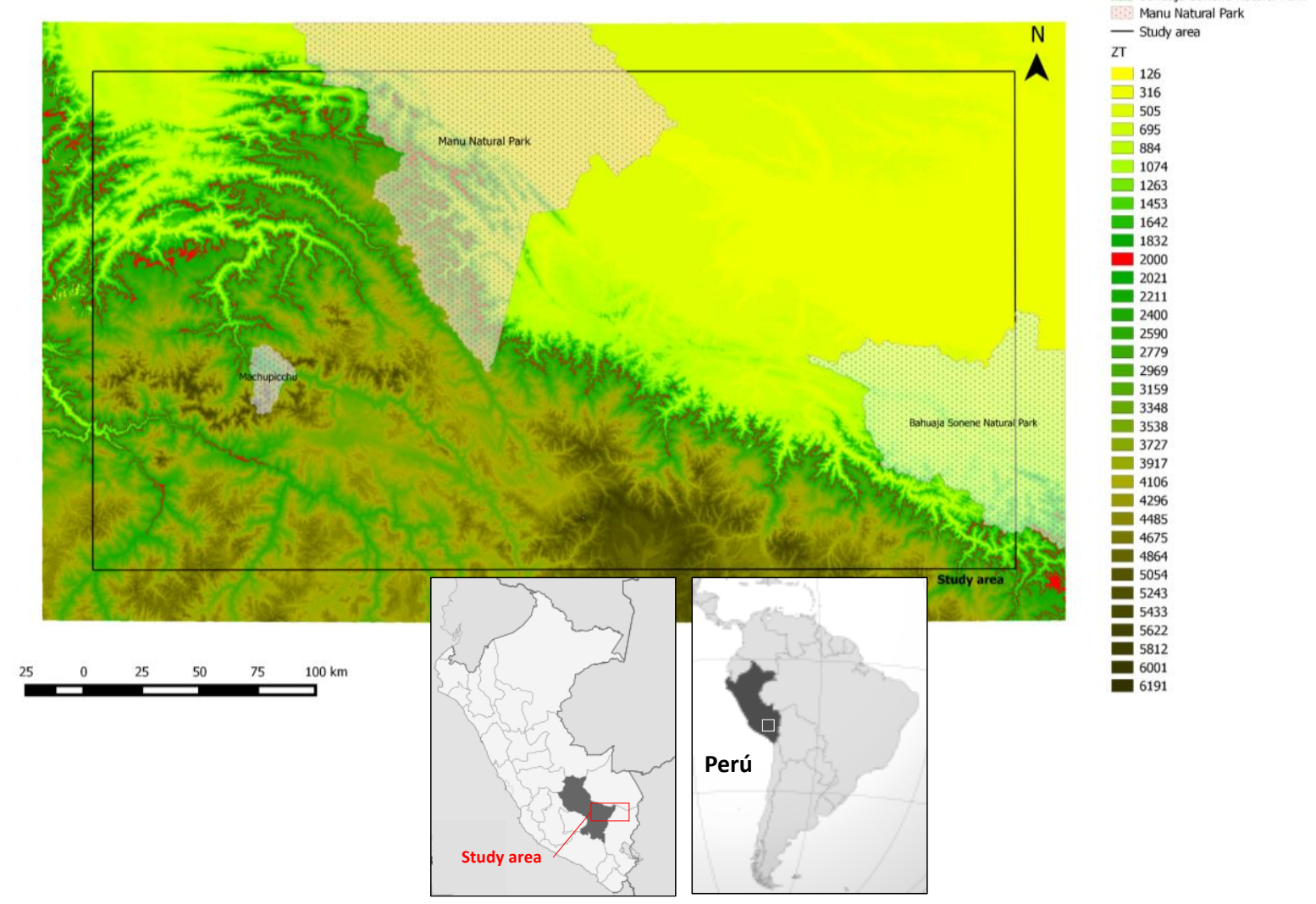

Figure 1. Location of the study area. Colour legend indicates altitude in meters a.s.l.

\section{Methodology}

\subsection{Data}

Three different sets of data were used: MODIS to develop the linear unmixing model, the ASTER Global Digital Elevation Model (GDEM) to develop an elevation mask over $2000 \mathrm{~m}$ a.s.l. at the study area and the Landsat TM5 for validation purposes.

MODIS instruments are onboard satellites Terra (EOS AM), launched in late 1999, and Aqua (EOS PM), launched in mid-2002; both following the Earth polar orbit and covering its entire surface every 1 to 2 days. MODIS instruments provide high radiometric sensitivity (12 bit) in 36 spectral bands, ranging from 0.4 to 14.4 microns wavelength, with spatial resolutions ranging from 250 to $1000 \mathrm{~m}$ (http://modis.gsfc.nasa.gov/about/design.php). Here, following the previous work of Anderson et al. (Anderson et al., 2005) we used the MOD09 product (MOD09GQ and MOD09GA) for obtaining the reflectance in the following wavelengths: band $1(620-670 \mathrm{~nm})$, band $2(841-876 \mathrm{~nm})$, band 3 (459$479 \mathrm{~nm})$, band $4(545-565 \mathrm{~nm})$, band $5(1230-1250 \mathrm{~nm})$, band $6(1628-1652 \mathrm{~nm})$ and band $7(2105-$ $2155 \mathrm{~nm}$ ). Bands 1 and 2 correspond to MOD09GQ and have a spatial resolution of $250 \mathrm{~m}$, while the other bands correspond to MOD09GA and have a spatial resolution of $500 \mathrm{~m}$. We also used the product MODIS $250 \mathrm{~m}$ land-water mask (MOD44W) to help us making a mask of water bodies. Images from 
MODIS were reprojected to WGS84/UTM18 using the Modis Reprojection Tool (MRT) free software (https://lpdaac.usgs.gov/tols/modis_reprojection:tool). MRT was also used to standarize pixel size to $250 \mathrm{~m}$ resolution in the three MODIS products (MOD09GQ, MOD09GA and MOD44W). For each MODIS product, we downloaded tiles h10v10 and h11v10 (that cover the study area) for the period January 2000-December 2012.

Aster is an earth observing sensor developed in Japan to be onboard the satellite "Terra". It is in operation since December 1999. Aster GDEM is a product from NASA and the Japan's Ministry of Economy, Trade and Industry, released on June 2009 and giving a complete mapping of $99 \%$ of the earth surface with a $30 \mathrm{~m}$ theoretical resolution. Previously the most comprehensive map was the NASA's Suttle Radar Topography Mission (SRTM) that covered 80\% of the Earth's surface with 90 $m$ resolution. Aster GDEM images can be obtained on the website:

http://gdem.ersdac.jspacesystems.or.jp/search.jsp. The ASTER images corresponding to the study zone (S13W074- S14W074- S13W073- S14W073- S13W072- S14W072- S13W071- S14W071S13W070- S14W070) were used to create an altitude mask to the MOD09GQ and MOD09GA reprojected images. After, another mask has been created by means of the MOD44W images to eliminate all water pixels. MODIS images used in the subsequent analysis had therefore a uniform $250 \times 250 \mathrm{~m}^{2}$ pixel size, were referred to the WGS84/UTM18 system and only non-water pixels above $2000 \mathrm{~m}$ a.s.l. were considered. All the algorithms developed to characterize endmembers, to perform the linear unmixing and to obtain the burned areas were implemented with MATLAB ${ }^{\circledR}$.

The Landsat TM5 (Landsat 5 Thematic Mapper, Landsat TM5) is a sensor flying aboard the Landsat 4 and 5 satellites, released in 1984 and decommissioned in June 2013. It performed a full observation of the Earth once every 16 days. This sensor provided information on reflectance in seven spectral bands: band $1(450-520 \mathrm{~nm})$, band $2(520-600 \mathrm{~nm})$, band $3(630-690 \mathrm{~nm})$, band $4(760-900 \mathrm{~nm})$, band 5 (1550-1750nm ), band 6 (10400-12500nm) and band 7 (2080-2350nm). Band 6 corresponds to the thermal band and has a resolution of $120 \mathrm{~m}$, while the other bands have a resolution of $30 \mathrm{~m}$. Landsat images corresponding to Path/Row 03/69 and 04/69 (covering the study area) were obtained on the website: http://glovis.usgs.gov/. These images were used to test the applicability of the LMM technique on higher resolution scenes. Data provided by Landsat is not directly the pixel reflectance value but the Digital Number (DN), therefore they have been converted to reflectance following the steps described on: https://earth.esa.int/ers/sysutil/069c.html.

\subsection{Endmembers characterization}

Three types of endmembers were used in this study: vegetation, soil and water (also referred to as shadow).

Each endmember requires a characteristic reflectance value per spectral band. To test the dependace of this value on the image tile and on time of the year (dry/rainy season), we randomly selected one cloud-free image per month for each MODIS product (MOD09GQ/GA) and tile (h10v10 and h11v10) for the period February 2000 - December 2012 (i.e. 620 images). In each image three areas of 5x5 $\mathrm{km}^{2}$ were selected, each area corresponding to pure vegetation, soil or water. The reflectance values for each of the three endmembers were statistically analyzed, individually for each spectral band and, as a function of the tile and whether it corresponded to the dry season (May to October) or to the rainy one (November to April). The results showed that no significant differences existed, neither among tiles nor among season. Therefore, mean global values for each endmember and spectral band were used (see Figure 2). 


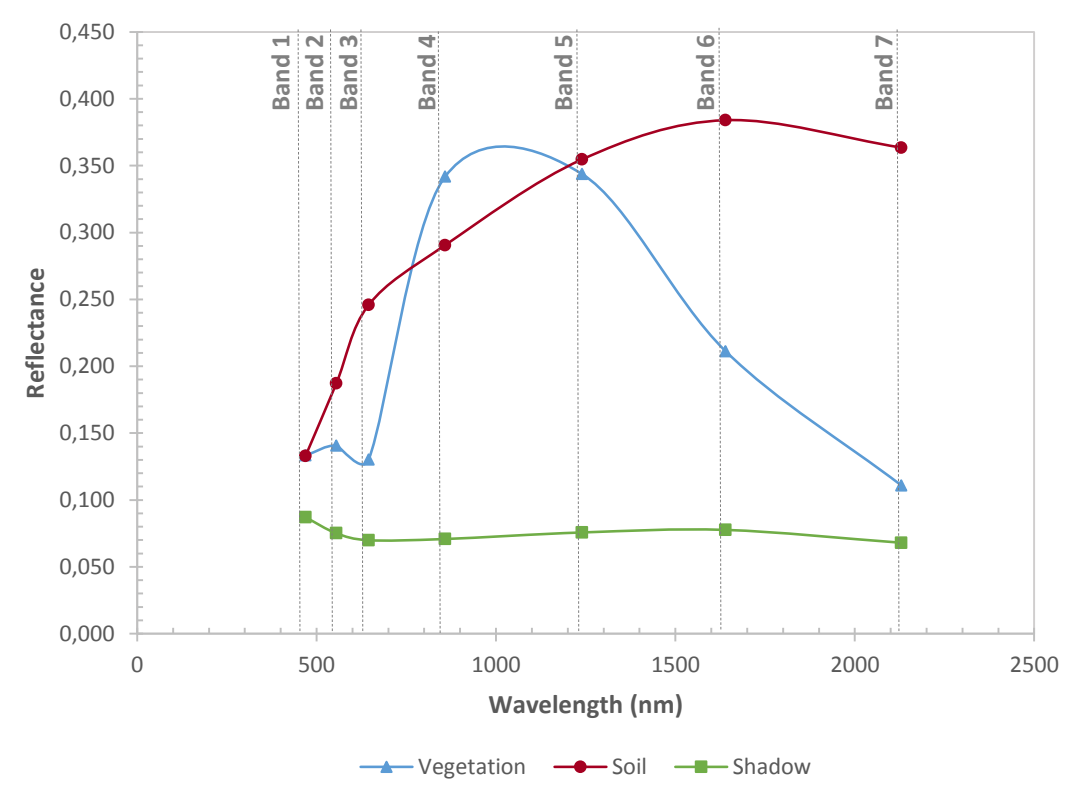

Figure 2. Reflectance values of the three endmembers used in the study as a function of the spectral band (from cloud-free images).

One of the main problems arisen in previous studies, that caused a low detection of the burn scars, was the large presence of clouds in the study area. To avoid that error, the endmembers were also characterized in those pixels identified as being medium cloudy -called "mixed"- and highly cloudy -called "cloudy"- (Figure 3).
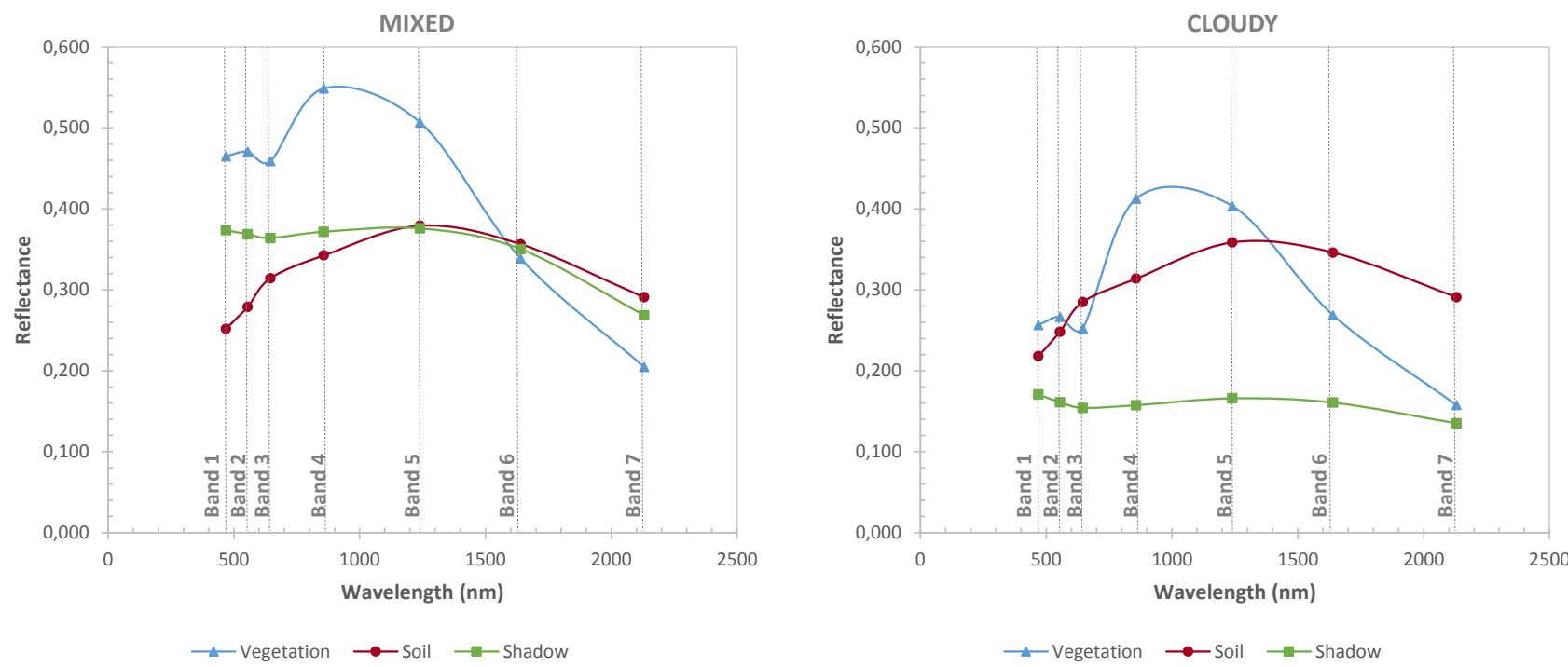

Figure 3. Reflectance values of the three endmembers used in the study as a function of the spectral band for pixels showing some degree of cloudiness. On the left values corresponding to mixed pixels; on the right values corresponding to cloudy pixels.

As it can be observed from the previous figures, there were clear differences between the reflectance of endmembers based on the degree of cloud cover. Being mixed pixels the ones that have the highest values and pixels free of clouds the ones that have lowest values. 


\subsection{Linear unmixing model}

The LMM used in this study can be represented by the following equation:

$$
r_{i}=a \cdot \text { vegetation }_{i}+b \cdot \operatorname{soil}_{i}+c \cdot \operatorname{shadow}_{i}+e_{i}
$$

Where $r_{i}$ is the reflectance of a pixel in the spectral band $i ; a, b$ and $c$ are the proportions of vegetation, soil and shade respectively in this pixel; vegetation ${ }_{i}$, soil $_{i}$ and $\operatorname{shadow}_{i}$ are the reflectance values of the three endmembers in the spectral band $i ; e_{i}$ is the error of band $i$.

For each pixel, depending on whether it is clear, mixed or cloudy, a set of seven linear equations was obtained (one for each spectral band with the corresponding endmembers as a function of the cloudiness) with three unknowns $(a, b$ and $c)$ and two constrains: $(a, b$ and $c \geq 0)$ and $(a+b+c=1)$. The least squares regression analysis was used to solve this system of linear equations.

Once the relative abundances of the three endmembers are known for each pixel, the burned areas can theoretically be recognised as made of pixels having large proportions of shade. In section 4 we show the analysis of two known burn scars in the study area (described in section 3.4) in order to identify the thresholds in the shadow abundance that allow defining a pixel as burned.

\subsection{Reference burn scars}

Two previously known burn scars were used in this analysis. One corresponded to a fire occurred between the $2^{\text {nd }}$ and $4^{\text {th }}$ of July 2012 (named BS2012 from now on) covering around 129 ha and the other corresponds to a larger fire occurred at the end of August 2008 (named BS2008 from now on) with an area of approximately 1410 ha. Figure 4 shows these two burn scars superimposed over a Google Maps image of the zone together with a grid corresponding to the MODIS pixel size and distribution. Location of both fires in the study area is also given in Figure 5, the centre of BS2012 can be found in coordinates $-13.23^{\circ} \mathrm{S},-71.57^{\circ} \mathrm{W}$; the centre of BS2008 can be found in coordinates: $13.81^{\circ} \mathrm{S},-71.58^{\circ} \mathrm{W}$.
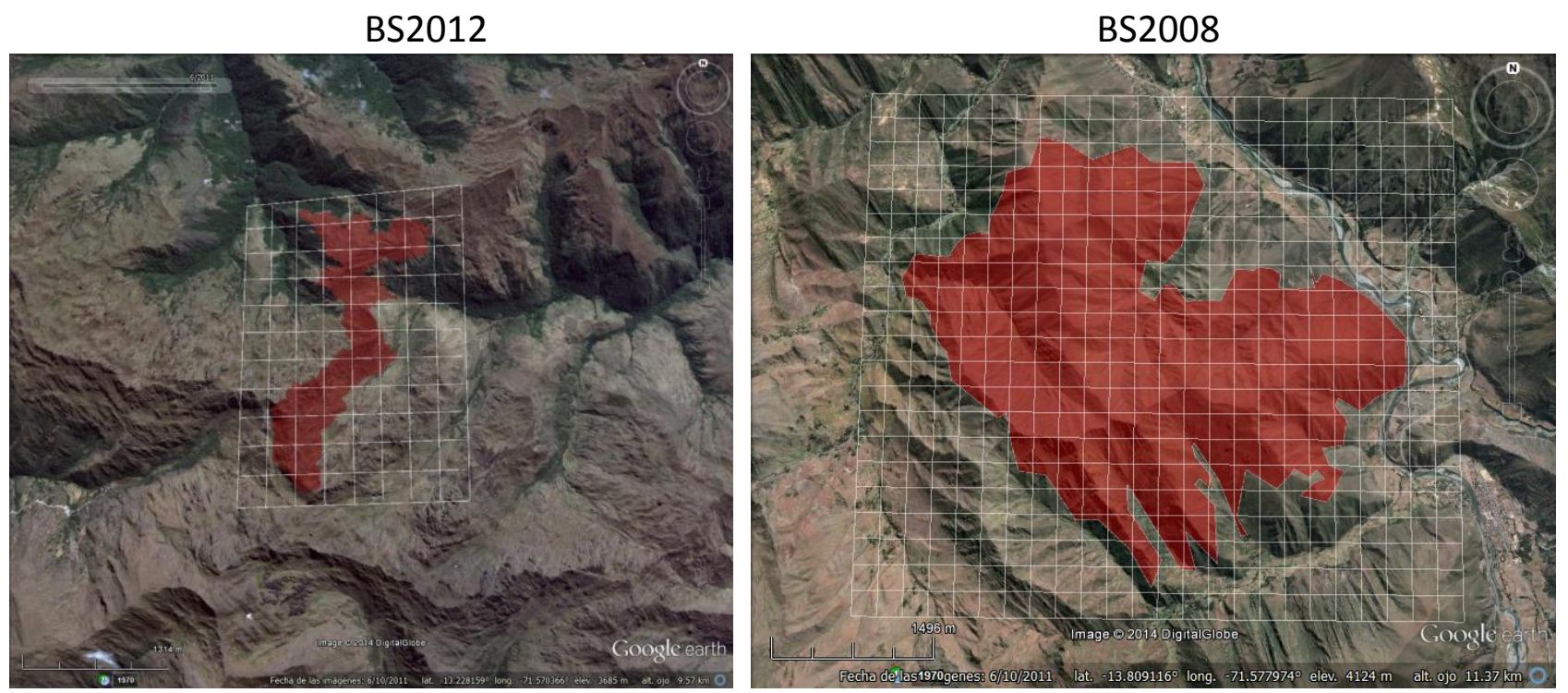

Figure 4. Area covered by the two burn scars used in this study. White line grid representing pixel size and number on the corresponding MODIS images. 


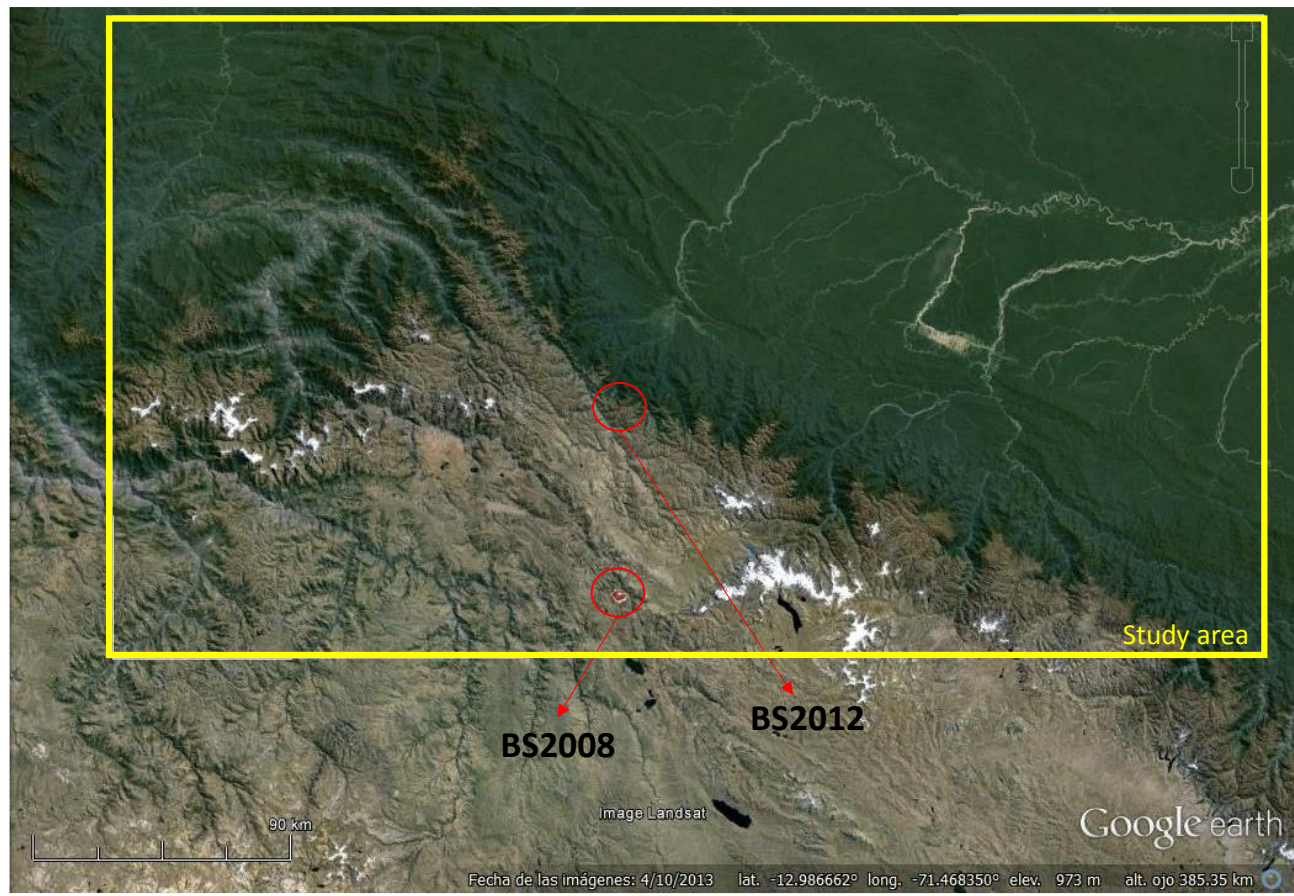

Figure 5. Location within the study area of the two burn scars used in this study.

Taking into account that MODIS pixel size is $250 \times 250 \mathrm{~m}^{2}$, BS2012 contained around 21 pixels while BS2008 contains around 226 pixels, which was a low number of data for any statistical analysis if only one image is taken. Therefore, 9 images corresponding to days previous to the BS2012 fire and 9 images just after the BS2012 fire were used to analyse the differences between burned and unburned pixels. In the case of BS2008, 5 images prior and 5 after the fire were used to extract the data.

\section{Results and discussion}

For each image previous and after the two fires analysed, BS2012 and BS2008, we obtained the abundances of the three endmembers considered: vegetation, soil and shadow. The frequencies of these abundances extracted from the images previous to the fire were plotted against the ones obtained after the fire. Because burned areas tend to have larger proportions of shadow (Anderson et al., 2005), we expected to see differences in the abundances distribution previous and after the fire.

a)

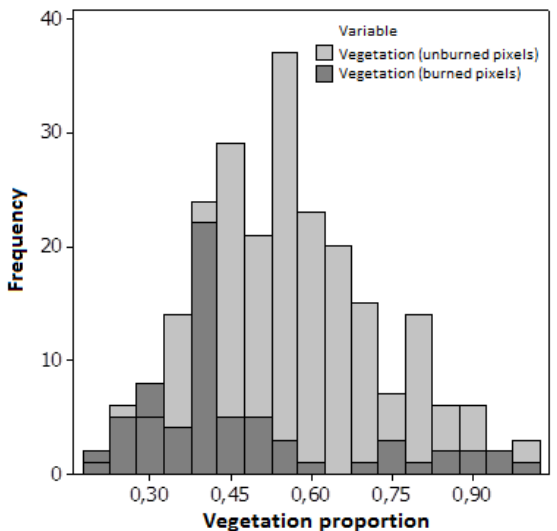

c)

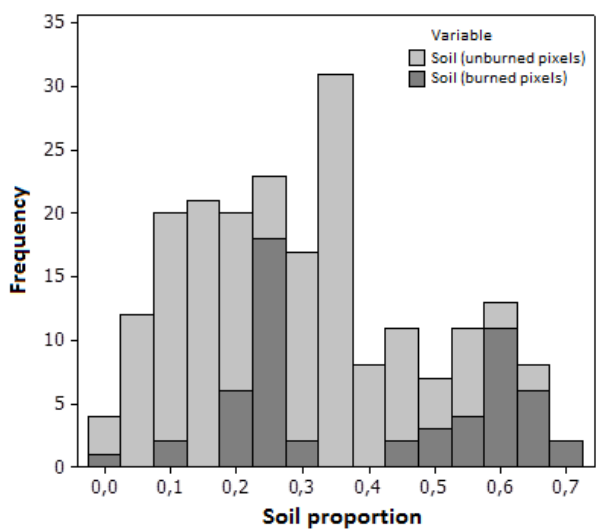

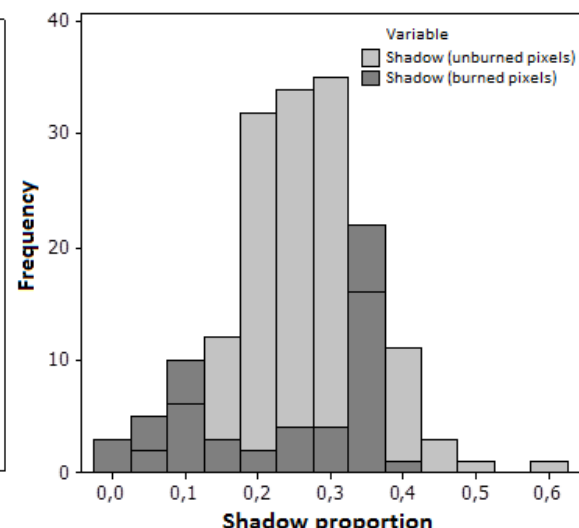

Figure 6. Frequencies distribution of the endmember abundances prior and after the fire BS2012: a) vegetation, b) soil, c) shadow. 
a)

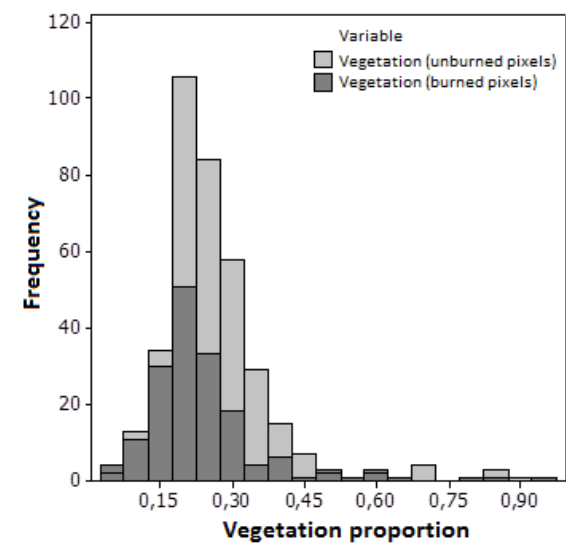

c)

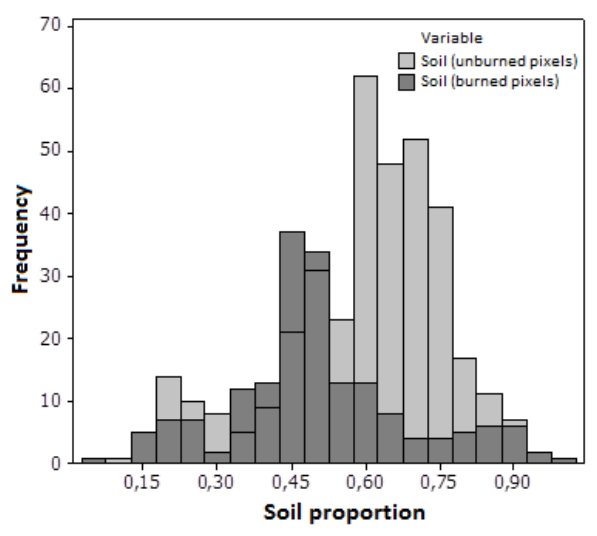

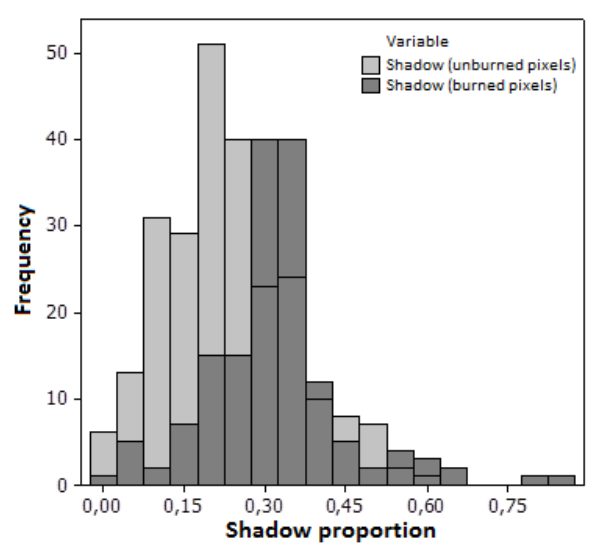

Figure 7. Frequencies distribution of the endmember abundances prior and after the fire BS2008: a) vegetation, b) soil, c) shadow.

Although vegetation abundances tended to diminish after the fire while soil and shadow abundances tended to increase, data dispersion was too large to enable us to distinguish a pixel from being burned or unburned according to its endmember proportion values (Figure 6). The large dispersion could be a result of the small size of the burn scar when compared to the pixel size, as there were many pixels that belonged to the burn scar boundary and were therefore half burned. Nevertheless, the same problem appeared inFigure 7, although in this case fire BS2008 was much larger and thus the boundary effect was smaller. These results show that that, even solving the problem of large presence of clouds in the area, linear unmixing method is unable to capture differences among MODIS reflectance values for burned and unburned pixels and therefore once again MODIS seems to fail to provide good data to obtain burn scar information in the study area. We hypothesized that MODIS spatial resolution was probably too low to capture with enough precision the differences in the reflectance values before and after the fire, taking into account the noise effect caused by the complex topography of the study area on the reflectance values.

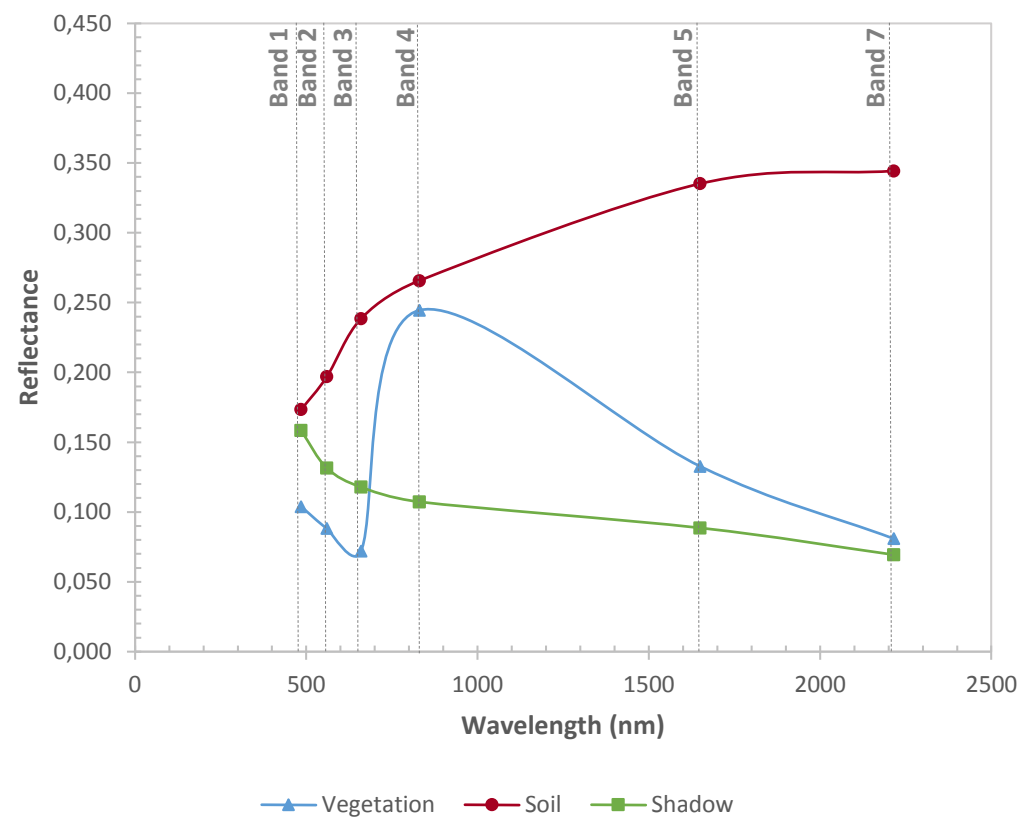

Figure 8. Endmembers characterization obtained from Landsat TM5 images. 
To test this hypothesis the same method was applied to images provided by Landsat TM5. A new endmembers characterization was performed following the method described in section 3.2, but using Landsat data on the spectral bands $1(485 \mathrm{~nm}), 2(560 \mathrm{~nm}), 3(660 \mathrm{~nm}), 4(830 \mathrm{~nm}), 5(1650 \mathrm{~nm})$ and $7(2215 \mathrm{~nm})$, Figure 8 shows the results obtained. In this case, the study of the endmember abundances distribution before and after the fire was performed with BS2008 whereas BS2012 was saved for validation purposes.

Figure 9 shows the endmember proportion before and after the BS2008 fire obtained with Landsat images. Results for soil and shadow abundances, showed large dispersion and a great number of extreme values, therefore not being useful for burned/unburned discrimination purposes. However, vegetation abundances were clearly different depending on whether the pixel was or was not burned. Burned pixels had a vegetation abundance below $40 \%$ while unburned pixels have always a vegetation percentage above $40 \%$. Using this criterion to distinguish between burned and unburned pixels, the method was applied to BS2012 in order to see if it was possible to detect the burn scar.

a)

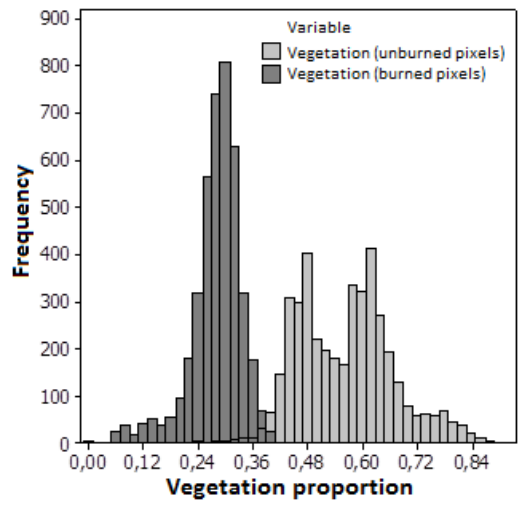

b)

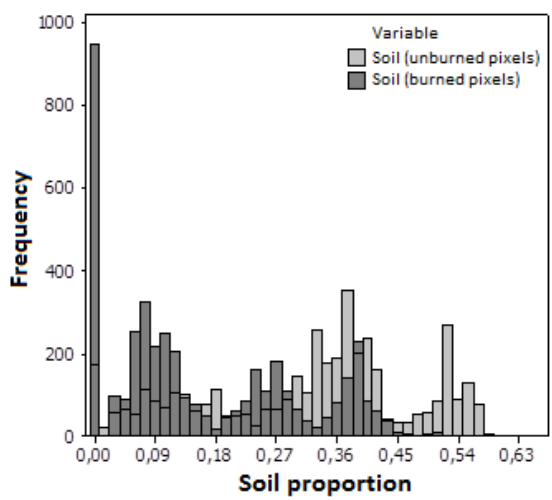

c)

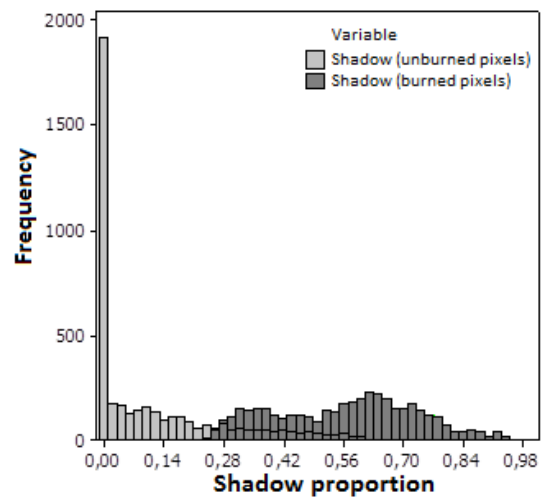

Figure 9. Frequencies distribution of the endmember abundances previous and after fire BS2008 using Landsat TM5 images: a) vegetation, b) soil, c) shadow.

Due to a number of difficulties that Landsat TM5 has been dragging since December 2008, no data was available for this sensor for the year 2012. Therefore, we used the images obtained by Landsat 7 $\mathrm{ETM}+$ that, despite the failure of one of their scanners, continues providing images. As it can be seen in Figure 10 (left and centre), Landsat 7 ETM+ images of the area were BS2012 was located show three black bands without data, due to problems with the sensor. This was transformed into three grey bands after applying the spectral unmixing model, corresponding to undefined pixels due to the lack of data. Despite this, the method was able to locate and draw the burn scar quite accurately. 


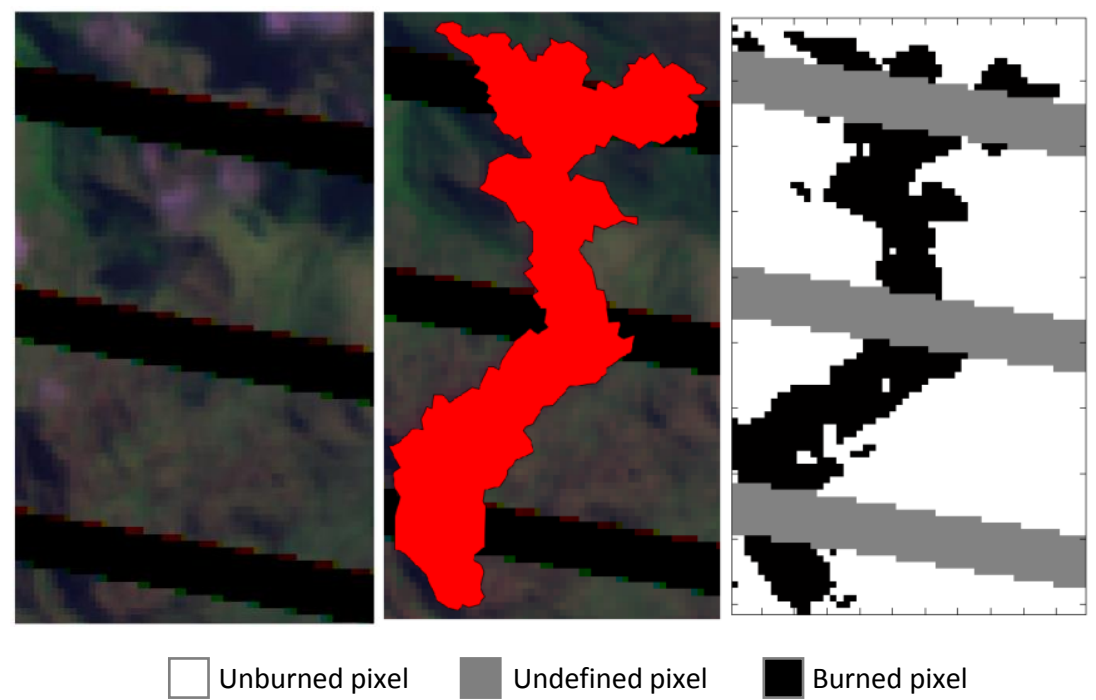

Figure 10. left: Landsat 7 ETM+ image prior to the BS2012 fire (16/06/2012); Centre: Landsat 7 ETM+ image after the BS2012fire (03/08/2012) with burn scar area superimposed; Right: image obtained with the linear unmixing model

An estimated value of $9 \%$ of commission error and $20 \%$ of omission error was computed for this fire, the only one for which the perimeter has been ground validated. Although omission error was still high, it significantly improved omission errors of $48 \%$ for the MODIS MCD45 burned area product in the study area (Oliveras et al., 2014).

\section{Conclusions}

The literature survey has shown that current methodologies to estimate burned areas in the tropical Andes need to be significantly improved. One of the methods that could provide better results is the spectral unmixing. This technique require the characterization of specific endmembers for the study area. In this paper a specific study to characterize the endmembers for the tropical Andes has been performed. It has shown that, for the study area, reflectance values of the endmembers are independent of the MODIS tile and of the season but change according to the degree of cloudiness.

MODIS images were not valid for the technique studied, probably due to their spatial resolution (250 $\mathrm{m})$. However, Landat images, with $30 \mathrm{~m}$ spatial resolution, proved to be relatively accurate in the detection of burned area scars with spectral unmixing modelling. However, the complex topography and meteorology of the study area makes the development of any automatized technique for detecting burned area scars especially challenging, and further efforts are needed to achieve a reliable, standardized method that allows the accurate detection of burned area scars in the tropical Andes.

\section{Acknowledgements}

This research was funded by the Spanish Ministerio de Economia y Competitividad under the project AGL2011-23425. The authors also thank the Autonomous Government of Catalonia for financial support (project No. 2009SGR1118). Authors are grateful to Erickson Urquiaga and Toño Quintano for providing the GPS perimeter of BS2012. Support has also been received from Asociación para la Conservación de la Cuenca Amazónica (ACCA) and Parque Nacional del Manu-INRAENA. 


\section{References}

Adams, J. B., \& Gillespie, A. R. (2006). Remote Sensing of Landscapes with Spectral Images. A Physical Modeling Approach (1st ed., p. 379). New York: Cambridge University Press.

Adams, J. B., Sabol, D. E., Kapos, V., Filho, R. A., Roberts, D. A., Smith, M. O., \& Gillespie, A. R. (1995). Classification of Multispectral Images Based on Fractions of Endmembers : Application to Land-Cover Change in the Brazilian Amazon. Remote Sensing of Environment, 52, 137-154.

Adams, J. B., Smith, M. O., \& Johnson, P. E. (1986). Spectral mixture modeling: A new analysis of rock and soil types at the Viking Lander 1 Site. Journal of Geophysical Research, 91(B8), 8098. doi:10.1029/JB091iB08p08098

Anderson, L. O., Aragão, L. E. O. e C. de, Lima, A. De, \& Shimabukuro, Y. E. (2005). Detecção de cicatrizes de áreas queimadas baseada no modelo linear de mistura espectral e imagens índice de vegetação utilizando dados multitemporais do sensor MODIS / TERRA no estado do Mato Grosso , Amazônia brasileira. Acta Amazonica, 35(4), 445-456.

Atkinson, P. M., \& Tatnall, A. R. L. (1997). Introduction Neural networks in remote sensing. International Journal of Remote Sensing, 18(4), 699-709. doi:10.1080/014311697218700

Ball, J. E., Kari, S., \& Younan, N. H. (2004). Hyperspectral Pixel Unmixing using Singular Value Decomposition. In IEEE Transactions on Geoscience and Remote Sensing. IEEE International Geoscience and Remote Sensing Symposium Proceedings (pp. 3253-3256). Anchorage, Alaska, Sept. 20-24, 2004: Institute of Electrical and Electronics Engineers, Inc.

Barducci, A., \& Mecocci, A. (2005). Theoretical and experimental assessment of noise effects on leastsquares spectral unmixing of hyperspectral images. Optical Engineering, 44(8), 087008. doi:10.1117/1.2010107

Bradley, A. V., \& Millington, A. C. (2006). Spatial and temporal scale issues in determining biomass burning regimes in Bolivia and Peru. International Journal of Remote Sensing, 27(11), 2221-2253. doi:10.1080/01431160500396550

Brown, M., Gunn, S. R., \& Lewis, H. G. (1999). Support vector machines for optimal classification and spectral unmixing. Ecological Modelling, 120, 167-179. doi:10.1016/S0304-3800(99)00100-3

Carpenter, G. A., Gopal, S., Macomber, S., Martens, S., \& Woodcock, C. E. (1999). A Neural Network Method for Mixture Estimation for Vegetation Mapping. Remote Sensing of Environment, 70, 138 152. doi:S0034-4257(99)00027-9

Chen, J., Jia, X., Yang, W., \& Matsushita, B. (2009). Generalization of Subpixel Analysis for Hyperspectral Data With Flexibility in Spectral Similarity Measures. IEEE Transactions on Geoscience and Remote Sensing, 47(7), 2165-2171. doi:10.1109/TGRS.2008.2011432

Cochrane, M. a. (2003). Fire science for rainforests. Nature, 421(6926), 913-9. doi:10.1038/nature01437

Du, Q. (2004). Optimal Linear Unmixing for Hyperspectral Image Analysis. In IEEE Transactions on Geoscience and Remote Sensing. IEEE International Geoscience and Remote Sensing Symposium Proceedings (pp. 3219-3221).

Elmore, A. J., Mustard, J. F., Manning, S. J., \& Lobell, D. B. (2000). Quantifying Vegetation Change in Semiarid Environments: Precision and Accuracy of Spectral Mixture Analysis and the Normalized Difference Vegetation Index. Remote Sensing of Environment, 73, 87-102. doi:S00344257(00)00100-0

Franke, J., Roberts, D. a., Halligan, K., \& Menz, G. (2009). Hierarchical Multiple Endmember Spectral Mixture Analysis (MESMA) of hyperspectral imagery for urban environments. Remote Sensing of Environment, 113(8), 1712-1723. doi:10.1016/j.rse.2009.03.018

Guilfoyle, K. J., Althouse, M. L., Chang, C., \& Member, S. (2001). A Quantitative and Comparative Analysis of Linear and Nonlinear Spectral Mixture Models Using Radial Basis Function Neural Networks. IEEE Transactions on Geoscience and Remote Sensing, 39(8), 2314-2318. 
Keshava, N., \& Mustard, J. F. (2002). Spectral Unmixing. IEEE Signal Processing Magazine, (January), 44-57.

Nascimento, J. M. P., \& Dias, J. M. B. (2005). Vertex Component Analysis : A Fast Algorithm to Unmix Hyperspectral Data. IEEE Transactions on Geoscience and Remote Sensing, 43(4), 898910.

Oliveras, I., Anderson, L. O., \& Malhi, Y. (2014). Application of remote sensing to understanding fire regimes and biomass burning emissions of the tropical Andes. Global Biogeochemical Cycles, 28, 480-496. doi:10.1002/2013GB004664

Román-Cuesta, R. M., Carmona-Moreno, C., Lizcano, G., New, M., Silman, M., Knoke, T., ... Vuille, M. (2014). Synchronous fire activity in the tropical high Andes: an indication of regional climate forcing. Global Change Biology, 20(6), 1929-42. doi:10.1111/gcb.12538

Sarmiento, F. O., \& Frolich, L. M. (2002). Andean Cloud Forest Tree Lines. Naturalness, Agriculture and the Human Dimension. Mountain Research and Development, 22(3), 278-287. doi:10.1659/0276-4741(2002)022[0278:ACFTL]2.0.CO;2

Settle, J. (2006). On the effect of variable endmember spectra in the linear mixture model. IEEE Transactions on Geoscience and Remote Sensing, 44(2), 389-396. doi:10.1109/TGRS.2005.860983

Somers, B., Asner, G. P., Tits, L., \& Coppin, P. (2011). Endmember variability in Spectral Mixture Analysis: A review. Remote Sensing of Environment, 115(7), 1603-1616. doi:10.1016/j.rse.2011.03.003

Somers, B., Delalieux, S., Verstraeten, W. W., van Aardt, J. a. N., Albrigo, G. L., \& Coppin, P. (2010). An automated waveband selection technique for optimized hyperspectral mixture analysis. International Journal of Remote Sensing, 31(20), 5549-5568. doi:10.1080/01431160903311305

Tompkins, S., Mustard, J. F., \& Forsyth, D. W. (1997). Optimization of Endmembers for Spectral Mixture Analysis. Remote Sensing of Environment, 59, 472-489. doi:S0034-4257(96)00122-8

Wang, F. (1990). Fuzzy Supervised Classification of Remote Sensing Images. IEEE Transactions on Geoscience and Remote Sensing, 28(2), 194-201. 